\title{
Optimizing the operational process of a cold chain fruit pack house
}

\author{
Adwoa Asantewaa Asante*, Ming Yin*, Cephas Kenneth Abbew and Divine Nyumuteye
}

Shanghai International Shipping Institute, Shanghai Maritime University, China.

College of Transport and Communications, Shanghai Maritime University, China.

Accepted 25 March, 2019

\begin{abstract}
The role of cold chain pack houses in preventing food from going bad is constantly becoming important. This is due to the growing concern of the world about food safety. However, cold-chain pack houses face numerous problems which prevent them from functioning effectively. This paper reviews studies relating to the cold chain and its importance as well as studies relating to the pack house. Flexsim simulation software is then used to model and simulate the operational activities and processes of a fruit pack house. The results obtained are analyzed to determine the idle resources and bottlenecks of the system. Adjustments are then made to the system to obtain better results which will contribute to the overall performance of the fruit cold chain.
\end{abstract}

Keywords: Cold-chain, pack house, operational process, modeling and simulation, Flexsim.

*Corresponding authors. E-mail: adjoaasantewaa14@yahoo.com and yinm@shmtu.edu.cn.

\section{INTRODUCTION}

Perishable foods are one of the rapidly developing segments of the grocery and food service industry (George, 2000:7). Sustained attainment depends on effective controlling of the "cold chain", a word use to define (George, 2000:7) a climate-controlled supply chain, consisting of production, storage, transportation and distribution activities which maintains a product (refrigerated and frozen) at a given ambient range in other to maintain the quality of the product until it reaches the final consumer (Challenges and Opourtunities, n.d.).

Control of the cold chain is essential to maintain the seniority of the product, freshness, alimentary values, active ingredients (Cold supply chain, 2012) and assures a cost-efficient distribution to the customers paying enough attention for customer service (Cold Chain, n.d., p. 1). The chain must begin at the farm house (example: harvesting methods, pre-cooling) and continue to the retailer or the final customer (Cold Chain, n.d., p. 1).

Hence, managing the cold chain necessitates invention, cooperation and communication to guarantee that all the key parties of the chain apprehends commodity storage and handling conditions (Reed,
2005). A perishable item can lose its value, integrity or stability if there is any loss of control at any point in time of the chain (Castiaux, 2010:29).

The refrigerated movement of perishable goods dates back to 1797 when British fishermen used natural ice to preserve their fish stockpiles from going bad while at Sea (Wang and Wang, 2005). In the late 1800's, this same process was also used in the movement of foods like dairy products from the rural areas to the urban centers for consumption (Cleland, 1996). In the late 1870's and early 1880's, cold storage became an important component of food trade between colonial masters and their colonies. For instance, New Zealand exported pork and other meat to Britain while Australia exported beef to Britain (James et al., 2006). Approximately, 600000 tons of frozen meat were being sent to Britain alone by 1910 (James et al., 2006).

In 1902, the first reefer ship for banana export was introduced by the United Food Company and this enabled exotic bananas which usually arrived on the market too ripped to be consumed, moved from a small market to one of the worlds most consumed fruit 
(Rodrigue and Notterboom, 2017). This had an outstanding significance on the reefer industry (Rodrigue and Notterboom, 2017).

Since the 1950's, the emergence of logistical third-party companies has played a key role in the development of the cold chain by the introduction of new methods for successfully storing, distributing and transporting these perishable goods globally (Craig, 2007:3). However, before the 1950's cold chain processes were being managed by manufactures themselves before the emergence of third-party logistics companies (Craig, 2007:3). For instance, in the United State of America, certain restrictions and accountability measures of the Food and Drug Administration about the stability of the cold chain induced many manufactures and companies who could not go by these rules and regulations to rely on special couriers and third-party logistical companies (Craig, 2007:3).

Specialization has not only brought about the reliance of companies on third party logistics providers but also the development of a more focused industry that have a niche logistical expertise in the packing, management, storage, distribution and transportation of perishable goods (Rodrigue and Notterboom, 2017). This has resulted in the growing level of specialization and segmentation of several potential niche markets in the cold chain logistics industry globally (Rodrigue and Notterboom, 2017).

The main objective of this paper is to identify certain problems in the operational process of a fruit pack house and how these problems can be solved in order to improve the overall performance of a fruit cold-chain. For this reason, the paper has been divided into six sections. After the first section which is an introduction comes the second section, a review of works pertaining to the cold chain and its importance as well as the pack house. Section three introduces the methodology used and section four presents the modelling of the operational process of the cold-chain fruit pack house. In the fifth section results are analyzed and improved while section six presents the conclusion of the research.

\section{LITERATURE REVIEW}

\section{Importance of the cold chain}

Per individuals rising interest about food security, the cold chain is playing a vital task in avoiding food from getting damaged (Zhu et al, 2014:270). This has induced many authors to come out with various (slightly) different importance of the cold chain, for instance: The cold chain is regarded as an enormous competitive advantage as it creates an appreciable extension to commodity shelf life which enables suppliers to enter foreign markets as well as satisfying local demand (Sundarakani et al., 2010).

Emphasizing on the importance of cold chain from the geographical perspective, Rodrigue and Notteborm (2017) highlights that the cold chain has three main influences which are: Global: The cold chain allows countries to concentrate in a specific agricultural field which allows the transportation and distribution of refrigerated foods from one point of the world to the other. Regional: The cold chain permits concentration of production and also enables countries to benefits from economies of scale notably in distribution; for instance, a large cold storage facility serving regional food market. Local: It allows perishable products to be distributed to customers on time and in good quality.

According to the research carried out in 2016 (2016 Top Markets Report Cold Chain, p. 4) by managing parameters of temperature, humidity and atmospheric composition, along with utilizing proper handling procedures, the cold chain can increase the life of fresh foods for days, weeks or even months. It allows fresh products to hold their value longer, increasing their transportability and providing opportunities that expand their market reach.

Dependable and well-organized cold chains contribute not only to decreasing food losses, but also to increasing the technological and operational efficiency of the food cold chain. Cold chains hence enable conformity with quality and safety conditions and increase market growth, accelerating increases in production. Improvement of the cold chain can therefore be counted as an essential step to attaining food and nutrition safety (FAO, and IIR, 2016).

NCCD (2015: 26-27) states the significance of the cold chain in two phases; as maintaining a commodity quality and as increasing the shelf life of the commodity. Maintaining a commodity quality is best demonstrated in circumstance where cold-chain knowledge is organized to mainly safeguard commodities from intemperate natural or ambient situations. This means that, the coldchain has more of a conserving result on the commodity it protects - there is no lengthening of commodity shelf life, only a function of conserving its state by keeping prearranged ambient parameters. These sorts of items include ice cream, meats, most processed foods, vaccines, many chemicals and plastics and electronic goods.

Increasing the shelf life of the commodity: when we reflect on the cold-chain for fruits and vegetables in garden-fresh form, principally living perishables, the produce under care benefits from an increased life cycle. The cold-chain when used appropriately, efficiently increases the commodities' living cycle and maintains nutrient quality.

Finally, according to Jobling (Correct cool chain), keeping the cold chain is significant for many reasons, all of which connects to preserving commodity quality. For instance, temperature has an absolute influence on the respiration rate of the commodity and this is a sign of the rate of deterioration of the commodity. Temperature also 
influences the degree of development of postharvest rots. If the cold chain is kept, all of these influences can be delayed and the shelf life can be increased and quality preserved.

Although the various importance of the cold chain differs, they do contain some similar specific elements. For instance, all the authors made mention of the cold chain increasing the shelf life of products whiles others added that the cold chain helps companies to access overseas markets. Thus, the most important benefit derived from the cold chain can be summed up to increasing the shelf life of products as well as maintaining the quality of it.

\section{Overview of a pack house}

Pack house has been defined in so many ways by different researches. Six definition has been selected which are more relevant to this study. A pack house is a facility for carrying out numerous activities such as cleaning, salting, grading, commodity treatment and packing that prepares a commodity for the market (Acedo and Weinberger, 2016: 12)

A pack house is a location where produce is conveyed to after harvesting, to prepare them as per the market needs in terms of washing, brushing, waxing, any other chemical treatment, grading, packing, cooling, storage and transportation (Banana Pack House, n.d. p. 1).

According to Acedo et al. 2016: 5, a pack -house is a physical structure where harvested produce is combined and prepared for transport and distribution to market.

NCCD (2015) define a pack house in terms of the modernity of it. A pack house is a modern infrastructure with facilities for conveyer belt system for sorting, grading, washing, drying, weighing, packaging, precooling and staging

Yaptenco and Esguerra (2012: 1) in their study referred to the term pack house as a selected facility where fresh produce is assembled and prepared in other to meet the needs of particular customers. In this contest market preparation operations or packing house operations are required. The pack house is the location where postharvest management is done and quality standards are checked.

Pilgrim (2010: 7) defined pack house as a protective unit where after harvest, horticultural produce is cleaned, sorted, sized, and usually packaged for sale in the fresh commodity market.

From the definition of the term, we can establish that, a pack house is a place (simple or modern structure) where various activities are done or performed to prepare produce for the market.

The pack house plays a critical role in the cold chain of specific vegetables and fruits; a salient focus on the pack house will ensure that fruits and vegetables are handled with care, the right quantity packed, and distributed to consumers as required in the shortest possible time.

Paltrinieri (n.d. p. 37), add that, the location for the packing processes may merely be the establishment of a convenient or provisional shelter in the field next to the harvesting area to safeguard the commodity and employees from the weather throughout field handling. This is of substantial significant for commodities harvested in hot, sunny states where contact with the weather for only a few hours can evidently quicken senescence or in rainy period when the risk of microbial contamination is largely enhanced if the commodity turns out to be wet (Paltrinieri, p. 37).

A pack house allows quality assertion activities that ensures that commodity quality and quantity meet the prerequisite of consumers and loses are reduced in the course of transport and delivery to consumers (Acedo et al., 2016: 6).

A pack house can function as a center for organization and governance of a farm-pack house-market organization in which consumer demand commands manufacturing and pack house activities (Acedo et al., 2016: 6).

A farm-pack house-market organization increases economy of scale; advances market access, and accelerate technical and business enlargement involvements. The farm-pack house-market organization can be accomplished by three teams: management team, production team and marketing team. These teams have to work faithfully to meet customer demand. The pack house is the pivot of a farm business. Appropriate running guarantees that the business will flourish in a maintainable mode (Acedo et al., 2016: 7).

\section{Methodologies/tools used to solve relevant problem}

Currently, research on cold-chain fruit pack houses are still in the early stages. Most researchers focus on the definitions (Banana Pack House, n.d.; Yaptenco and Esguerra, 2012; Acedo et al., 2016; Acedo and Weinberger, 2016), importance (Yaptenco and Esguerra, 2012; Acedo et al., 2016), design (Acedo et al., 2016; Yaptenco and Esguerra, 2012; Pilgrim, 2010; Balls, n.d.) and the operational processes (Kitinoja and Kader, 2003; Hassan et al., 2015; Paltrinieri, n.d.; Yaptenco and Esguerra, 2012; Acedo et al., 2016; Acedo and Weinberger, 2016; Balls, n.d.) of a pack house. Meanwhile, there are so many problems in the operational processes of a cold-chain fruit pack house that needs to be identified and rectified to improve the overall performance of fruit pack house. The modelling of a cold chain pack house is a type of random discrete event system and approaches such as spreadsheet models, mathematical programming and queuing theories cannot be used hence the need for simulation models (Beukes, 2011). Simulation techniques can show specific 
status and find out the bottleneck and idle resource of the system which gives a detail description about actual process and information of a logistics system (Zhu et al., 2014). Experts like (Beukes, 2011) have used simulation to create a generic model to assist in the design of a citrus pack house. Zhu et al. (2014) also used simulation to model the operational process of a cold chain distribution center.

In the management of complex systems such as production lines within packaging, sorting and distribution facilities, conventional approaches have fared inadequately, requiring the adoption of more comprehensive approaches to analyzing the individual components.

Simulation protocols unlike spreadsheet modelling and other operations research tools are able to analyze more concisely finding interdependencies between the different components on a production line. Simulation processes outperform other models in its ability to pinpoint areas where bottlenecks exist as well as others displaying peak performance to enable targeted optimization. For instance, simulations methods are able to detect and compute performance of each machine within a given production line.

\section{MODELLING}

Because of the objectives of this research and its significance, Flexsim simulation software was used in building the case study. FlexSim is a mighty analysis tool that aids engineers and planners make smart choices in the design and operation of a system. With FlexSim, an individual can develop a 3-dimensional computer model of an actual system, and then review that system in a shorter time period and for less cost than with the real system (FlexSim 3D Simulation Software, 2014: 16).

\section{Modelling for the operational process of a cold-chain fruit pack house}

From the field study, the pack house normally performs the function of unloading, gathering, checking and inspection of fruits, washing and chemical treatment, sorting, tallying, labeling, packing and temporarily storage of fruits. The internal operational process of the pack house has five main steps including arrival of fruits, circulating and processing, packing and labeling, palletization and temporary storage. Several setbacks may take place during these processes; the setbacks which include the relevant context of working environment are difficult (Ke, 2013).

Based on the above investigations and reflecting on the reality, the pack house has resources such as temporary storage facility (pre-cooler), packing line, workers, weight checking machine and pallet truck. The pack house is divided into five areas which are arrival area, circulating and processing area, packing and labeling area, palletization area and temporary storage area. The specific areas are below:

Arrival area: This area includes unloading, checking and inspection of fruits. There is physical examination of fruits by workers who pick fruits at random to make sure that a fruit meets the required standards. Fruits that do not meet the required specifications are rejected. Elements needed here are workers.

Circulating and processing area: This area always deals with fruits from the arrival area. The activities performed here include washing (chlorine bath), chemical treatment, waxing, fanning to dry up fruits and weighing of fruits. The elements involved in this area; packing line (water tank, conveyors, fans, chemical treatment machine, waxing machine) and workers.

Packing and labeling area: This area is used for sorting and packing of fruits into boxes according to weights, color and customer requirement. Each fruit is also labeled. This area includes elements such as automatic weighing and sorting machine, workers and conveyors (rollers).

Palletization area: This is where boxes of fruits are packed onto pallet according to color and sizes of fruits in the box, corner buttoning of the pallet, strapping and stamping of boxes. The elements found in this area are workers.

Temporary storage area: This is where the overall weight of each palletized cargo is checked and then moved into a pre-cooler for temporarily storage awaiting a refrigerated truck to the port or other locations. The elements needed here are weight checking machine, pallet truck and workers.

\section{SIMULATION TARGET}

The main simulation target of this research paper is the operation capability indication or performance of the pack house (efficiency of workers and equipment) in order to figure out the bottlenecks and idle resources of this operational system and improve upon it hence total output.

\section{Operation parameters and simulation components}

By collecting data from the field, many codes were written according to the various areas and parts of the pack house before the model can run with regards to this study. These are:

\section{Simulation time}

The simulation time unit is 1 second hence the total simulation working time is 28800 seconds ( 8 hours) per 
day, which reflects the normal working hours.

\section{Connections}

In line with the system process, connections $\mathrm{A}$ and $\mathrm{S}$ are used to link up the objects.

\section{Arrival area}

The inter-arrival time of flow items (boxes) follows a "Johnson bounded distribution of (1.338652, 2.221466, $0.050331,0.678434,0) \mathrm{sec}$, which was generated from the FlexSim simulation software. Flow items (boxes) arrives continuously during simulation and the number of flow items produced per day/ simulation is 15000 , to achieve this, a program code is written in triggers of "Source1".

\section{Circulating and processing area}

The system requires that "Operator1" picks 10 flowitems at a time and drops them in "Processor1" until it amounts to 600 flowitems, which will be processed at a time. To achieve this, "Perform Batching" function of "Queue" is activated and the "Target Batch Size is set at 10. To enable "Processor1" to accumulate and process 600 flowitems at a time, an "AccumQueue" is positioned on top of "Processor1" and the "Maximum Content" of "AccumQueue" is set at 600 with the "Perform Batching" function activated and the "Target Batch Size" set at 600.The various codes written below shows the time each processor at circulating and processing area deals with flow items.

"Processor 1" = "Johnson bounded (1.739430, $3.210532,0.061744,0.745618,0)$ " sec.

"Processor 2" = "Johnson bounded (2.769649, 3.563632, -0.540886, 0.960167, 0)" sec.

"Processor 3" = "Weibull $(0.000000,0.674774$, $4.787375,0)$ " sec.

"Processor 4" = "Weibull $(0.000000,0.674774$, $4.787375,0)$ " sec.

"Processor 5" = "pearsont5 $(0.175855,0.882742$, $2.006148,0)$ " sec.

"Processor 6" = "pearsont5 (0.194801, 0.889721 , 2.014709, 0)" sec.

"Processor 7" = "pearsont5 (0.214599, 0.891060, $2.016348,0)$ " sec.

The system also requires that on an average 1500 flowitems should be rejected, hence the following codes are written in OnEntry in Triggers of "Sink25"

"Action $=$ closeinput

Object $=$ current
Condition = getinput (current) $\geq 1500 "$.

The main function enabled by the above code is that," Sink25" should always accumulate 1500 flow items.

\section{Packing and labeling area}

The codes below are written on Queues 8, 9, 10, 11, 12 and13.

"treenode current = ownerobject(c);

int port $=$ parval (2)

treenode dispatcher = center object(current,1); // the dispatcher or task executer

double priority = getvarnum (current, "transportpriority"); // read the Priority value on the GUI

int preempting = getvarnum (current, "preempt transport"); // read the Preemption mode on the GUI

treenodets $=$ createemptytasksequence (dispatcher, priority, preempting);

inserttask (ts, TASKTYPE_TRAVEL, current, NULL); inserttask (ts, TASKTYPE_FRLOAD, item, current, port);

inserttask (ts, TASKTYPE_BREAK, NULL, NULL);

inserttask (ts, TASKTYYPE_TRAVEL, outobject (current, port), NULL);

inserttask (ts, TASKTYPE_FRUNLOAD, item, outobject (current, port), opipno (current, port));

dispatchtasksequence(ts);

return 0;".

The main function enabled by the above codes is as follows: Operators will have to pick 20 totes at a time from Queues onto Queues and then fill each tote with specific quantity of flowitems (boxes) which they will carry to Conveyors respectively.

\section{Palletization area}

"Use Transporter" function on "Queue 14" is activated to trigger "Operator" to pick pallet from it onto "Combiner" and pack totes on the pallet.

\section{Temporary storage area}

"Use Transporter" function on and "Processor8" are activated to enable "Task executer" to carry pallet with totes from "Combiner7" to "Processor8" and to "Sink2" (Table 1).

Corresponding to the analysis of the operational process of the cold-chain fruit pack house, this research paper used flow chart to build the system model. More so, the model is the simulation module for the operational process of the cold-chain fruit pack house. Evaluated with the real operational process of the cold chain fruit 
Table 1. The components of simulation model.

\begin{tabular}{|c|c|c|}
\hline Name of elements & Type & Remark \\
\hline Source 1 & Producer & Producer of items \\
\hline Source 2 & Producer & Producer of totes \\
\hline Source 3 & Producer & Producer of pallets \\
\hline Processor 1 & Processor & Processor of receiving bay \\
\hline Processor 2 & Processor & Industrial fan 1 \\
\hline Processor 3 & Processor & chemical treatment machine \\
\hline Processor 4 & Processor & Waxing machine \\
\hline Processor 5 & Processor & Industrial fan 2 \\
\hline Processor 6 & Processor & Industrial fan 3 \\
\hline Processor 7 & Processor & Industrial fan 4 \\
\hline Processor 8 & Processor & Pallet weight checking machine \\
\hline Conveyor 1 & Conveyor & Receiving-processing conveyor \\
\hline Conveyor 2 & Conveyor & Industrial fan 1- pen treatment machine conveyor \\
\hline Conveyor 3 & Conveyor & Chemical treatment machine -waxing machine conveyor \\
\hline Conveyor 4 & Conveyor & Conveyor for items with weight 6 \\
\hline Conveyor 5 & Conveyor & Conveyor for items with weight 5 \\
\hline Conveyor 6 & Conveyor & Conveyor for items with weight 4 \\
\hline Conveyor 7 & Conveyor & Conveyor for items with weight 3 \\
\hline Conveyor 8 & Conveyor & Conveyor for items with weight 2 \\
\hline Conveyor 9 & Conveyor & Conveyor for items with weight 1 \\
\hline Operator 1 & Operator & Operator for receiving bay \\
\hline Operator 2 & Operator & Operator for receiving-processing conveyor \\
\hline Operator 3 & Operator & Operator for receiving-processing conveyor and industrial fun 1 \\
\hline Operator 4 & Operator & Operator for items with weight 6 \\
\hline Operator 5 & Operator & Operator for items with weight 5 \\
\hline Operator 6 & Operator & Operator for items with weight 4 \\
\hline Operator 7 & Operator & Operator for items with weight 3 \\
\hline Operator 8 & Operator & Operator for items with weight 2 \\
\hline Operator 9 & Operator & Operator for items with weight 1 \\
\hline Operator 10 & Operator & Operator for palletization \\
\hline Task Executer 1 & Transporter & Transporter of pallet with totes \\
\hline Sink 1 & Sink & Place for rejected items \\
\hline Sink 2 & Sink & Place for temporarily storage \\
\hline
\end{tabular}

Source: Field Study 2017.

pack house, the simulation module is acceptable (Figures 1 and 2).

\section{DATA ANALYSIS}

Simulation and results analysis for the operational process of a cold-chain fruit pack house based on Flexsim.

\section{Output and analysis of the results}

By using the Flexsim software and running the simulation model, this research paper obtains the results of working state statistics of machines, conveyors and workers.

The busy rate of Processor 2 and Processor 8 are very low. This implies that the efficiency of these Processors are very low.

The block rate of conveyors $1,4,5,6,7,10,11,12,13$ and 14 are high. This implies that the equipment and staff of these conveyors do not deal with items on time, in other words, equipment and staff of these areas are not enough. The empty rate of conveyors $2,3,7,8,9,14,15$ are high. This shows that there is always a backlog of items in equipment.

The idle rate of all the operators are very high. This signifies that there are bottlenecks in their various areas 


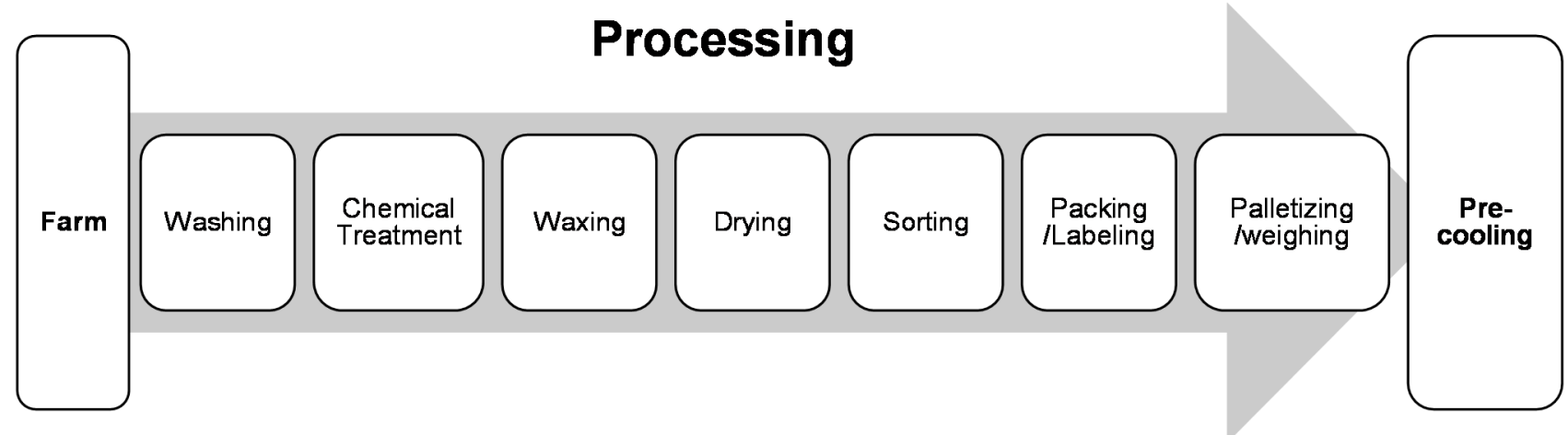

Figure 1. The operational process of a cold chain fruit pack house (Field Study, 2017).
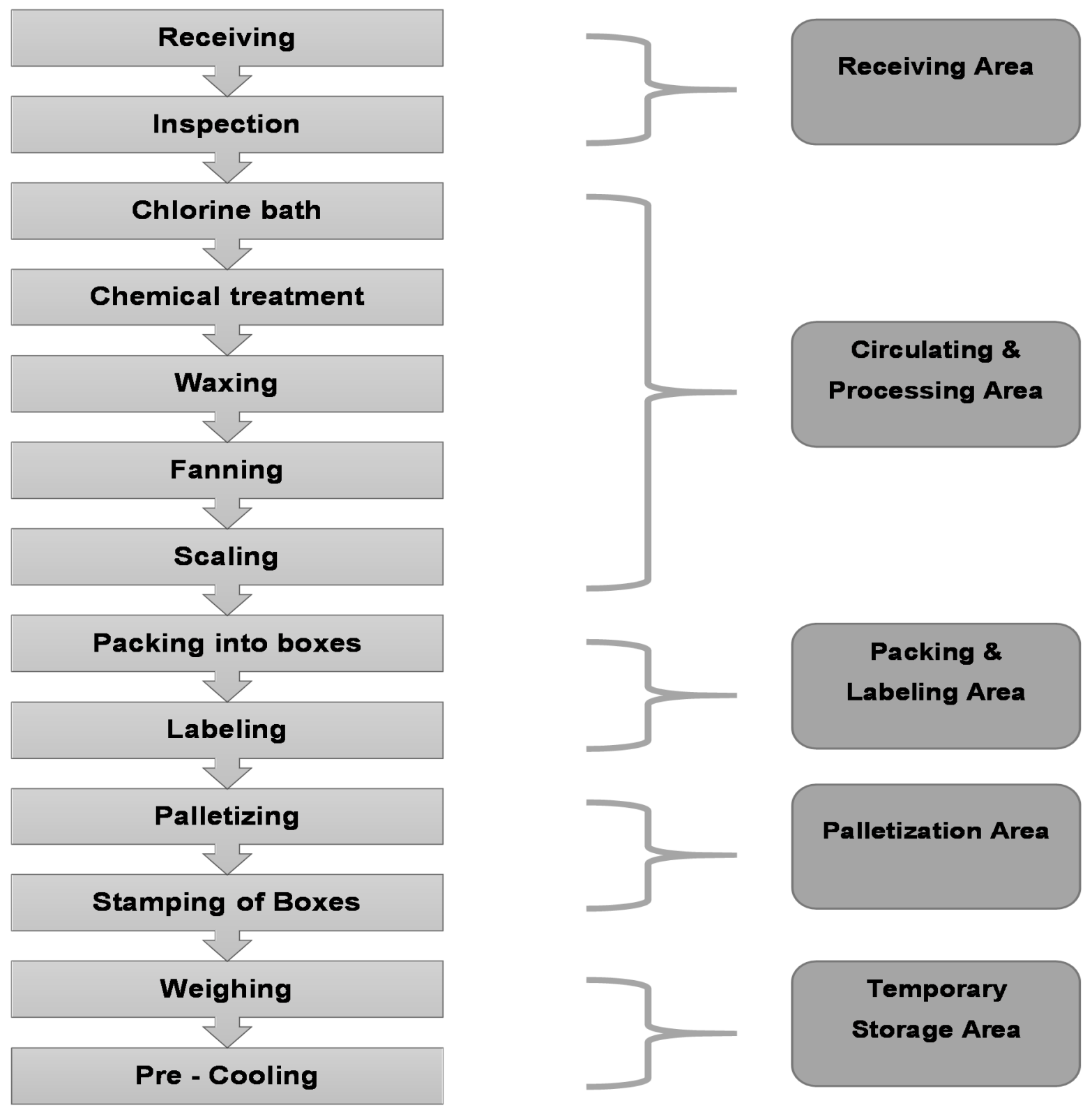

Temporary

Storage Area

Figure 2. A flow diagram and a simulation model on the operational process of the pack house (Field Study, 2017). 


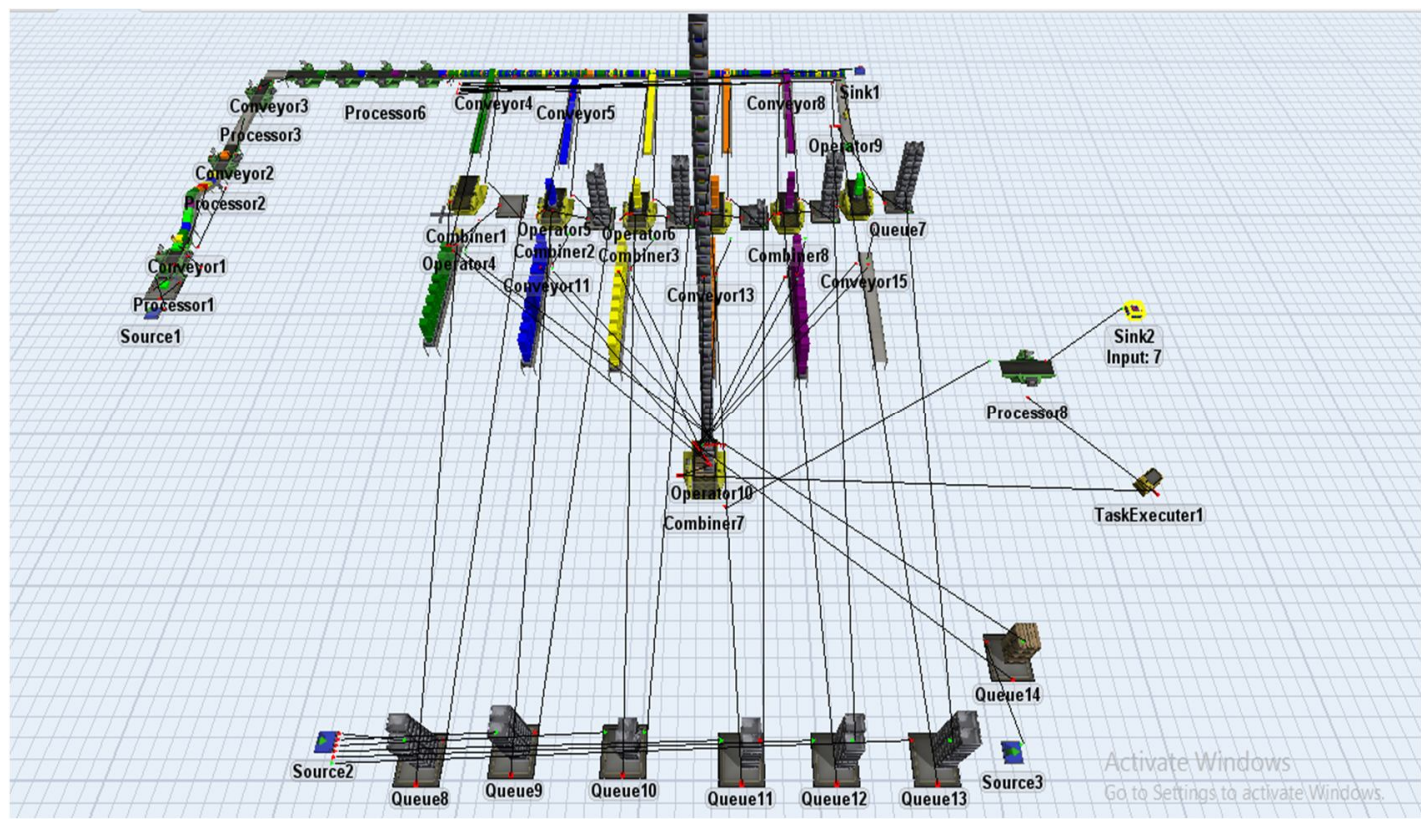

Figure 3. Total output before improvement (Field Study, 2017). The total output before simulation amounted to seven pallets (560 totes).

of operation (Figure 3).

\section{Improvement for the operational process of the fruit pack house}

\section{Picking system}

The accumulation of items at the receiving bay until it amounts to 600 items before it starts processing has been stopped. This is because it makes other objects idle until processing of the 600 items are done. This has been corrected with the continuous processing of 10 items from Operator 1 while operator 2 has been ejected.

\section{Packing strategy}

The packing of items into boxes were being done in ascending order from the merge sort's position which affected operations at the packing area. This is because the operator who packs higher quantity of items is stationed farther away from the mergesort. The packing system was corrected and it is now done in descending order from the merge sort's position such that the operator packing higher quantity is situated closer to the mergesort, hence solving the distance issue which was associated with packing.

\section{Palletizing}

The workload on Operator 10 was very high which was caused by the accumulation of totes on conveyors. This has been corrected with an additional Operator by the use of Experimenter function and hence operator 2 (Figure 4).

The total output after improvement amounted to twenty pallets (1600 totes). This shows a plus thirteen increase. This shows a massive increase in production within eight hours (28800 seconds).

\section{Performance with different parameters}

Based on the optimal results obtained different parameters were set in the system to validate the authenticity of the optimal result. To achieve this the model is set under different sets of input data. The bin for carrying fruits at the arrival area can accumulate ten fruits or less than that at a time. Accumulation of extra fruits in the bin will lead to the damage of fruits. This implies that Operator 1 can pick ten fruits or less than that into Processor 1. Every input data is kept constant while the target batch size being picked by Operator 1 and the maximum content of the "AccumQueue" is varied for three scenarios.

\section{Scenario 1}

With scenario 1, "Operator1" picks 5 - 7 flowitems at a time and drops them in "Processor1" until it amounts to 300 flowitems, which will be processed at a time. To achieve this, "Perform Batching" function of "Queue" is activated and the "Target Batch Size is randomly set between 5 and 7. To enable "Processor1" to accumulate 


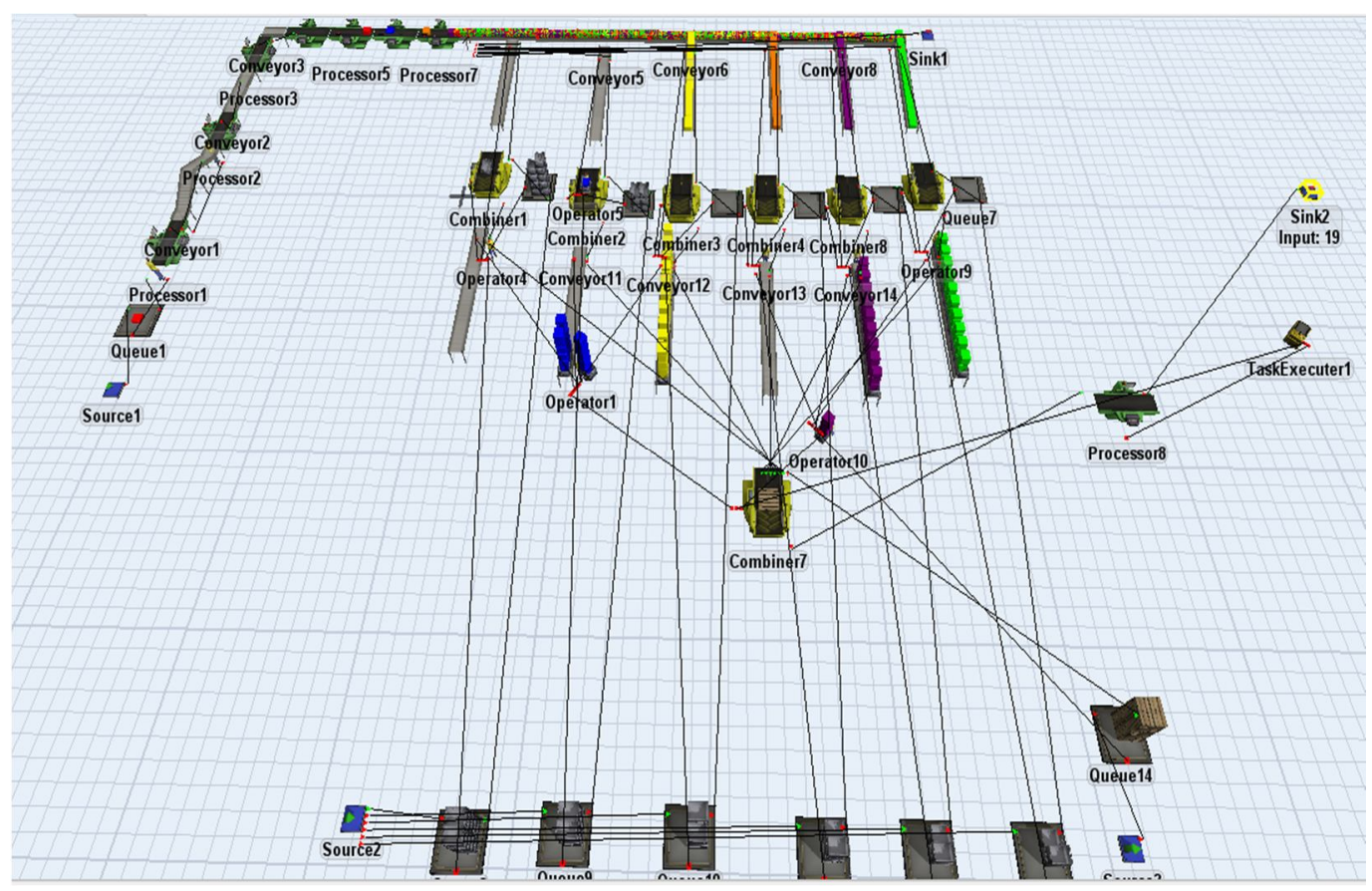

Figure 4. Total output after improvement (field study, 2017).

and process 300 flowitems at a time, an "AccumQueue" is positioned on top of "Processor1" and the "Maximum Content" of "AccumQueue" is set at 300 with the "Perform Batching" function activated and the "Target Batch Size" set at 300.The main bottleneck found here was the idle time of Operator 1 which was very high. The total output amounted to 10 pallets ( 800 totes).

\section{Scenario 2}

"Operator1" picks 10 flowitems at a time and drops them in "Processor1" until it amounts to 900 flowitems, which will be processed at a time. To achieve this, "Perform Batching" function of "Queue" is activated and the "Target Batch Size is set at 10.To enable "Processor1" to accumulate and process 900 flowitems at a time, an "AccumQueue" is positioned on top of "Processor1" and the "Maximum Content" of "AccumQueue" is set at 900 with the "Perform Batching" function activated and the "Target Batch Size" set at 900. The results showed that Processor 1 was always busy with a busy rate of $90 \%$ while Processor 2 and 8 had low busy rate. The idle rate of all the operators were very high except Operator 2 which recorded a travel rate of $70 \%$. The bottlenecks from scenario 2 were from Processor 2 and 8 as well as all the operators except Operator 2. The total output decreased to 4 pallets (320 totes).

\section{Scenario 3}

The system requires that "Operator1" picks 10 flow items at a time and drops them in "Processor1" until it amounts to 20 flowitems, which will be processed at a time. To achieve this, "Perform Batching" function of "Queue" is activated and the "Target Batch Size is set at 10. To enable "Processor1" to accumulate and process 20 flowitems at a time, an "AccumQueue" is positioned on top of "Processor1" and the "Maximum Content" of "AccumQueue" is set at 20 with the "Perform Batching" function activated and the "Target Batch Size" set at 20. The bottleneck of this system was from Operator 10 which had a high workload as a result of the accumulation of totes on conveyors $4,5,6,7,8$ and 9 . However, the total output amounted to 15 pallets (1200 totes) (Table 2).

From the scenarios above it can be seen that accumulating of fruits at the receiving bay before processing has a greater effect on the overall performance of the packhouse. This is because it makes other objects idle until processing of a particular batch of fruits is done. Continuous processing of 10 items from Operator 1 and stationing of Operator 2 at the palletizing area amounted the highest output which is 20 pallets (1600 totes).

\section{CONCLUSIONS}

This study was undertaken with a fruit producing company to identify certain problems in the operational process of a pack house. Flexsim simulation software was used to model and simulate the operational activities and processes of the fruit pack house. The results 
Table 2. Comparison of results for different scenarios.

\begin{tabular}{lccll}
\hline Scenario & Target batch size & Maximum content of "AccumQueue" & Operator 2 & Total output \\
\hline Scenario before improvement & 10 & 600 & idle & 7 pallets \\
Scenario after improvement & 10 & 10 & absent & 20 pallets \\
Scenario 1 & $5-7$ & 300 & idle & 10 pallets \\
Scenario 2 & 10 & 900 & idle & 4 pallets \\
Scenario 3 & 10 & 20 & busy & 15 pallets \\
\hline
\end{tabular}

Field study (2017).

obtained were analyzed to determine the idle resources and bottlenecks of the system. Adjustments were made to the system to obtain better results which will contribute to the overall performance of the fruit cold chain. In future, further studies should be carried out to determine a sorting area (based on customer requirements) for the pack house.

\section{REFERENCES}

Acedo A, Rahman M, Buntong B, Gautam D (2016). Establishing and managing smallholder vegetable packhouses to link farms and markets. Taiwan: AVRDC - The World Vegetable Center.

Acedo A, Weinberger K (2016). Vegetables postharvest: Simple techniques for increased income and market. Cambodia: AVRDC The World Vegetable Center, Taiwan and GTZ-Regional Economic Development Program.

Balls R (n.d.). Packhouse Design and Operation.

Banana Pack House (n.d.). Retrieved March 17, 2017, from mpstateagro.nic.in/Project\%20Reports\%20pdf/BANANA\%20PACK\% 20HOUSE.pdf.

Castiaux E (2010). An Introduction to Cold Chain Management. Journal of GXP Compliance, 14(4).

Challenges and Opportunities, Cold Chain - India. (n.d.). Retrieved February 24, 2017, from http://www.crosstree.info/Documents/ChOCold\%20Chain\%20India.p df

Cleland A (1996). Package Design for Refrigerated for Refrigerated Food: The Need for Multidisciplinary Project teams. Trends in Food Science \& Technology.

Cold Chain, Global AgriSystem. (n.d.). Retrieved February 24, 2017, from

http://mpstateagro.nic.in/Project\%20Reports\%20pdf/Cold\%20Chain.p df.

Cold supply chain management (2012). Retrieved February 24, 2017, from https://www.slideshare.net/yagyatichauhan/cold-supply-chainmanagement.

Craig M (2007). The Effects of Cold Chain Logistics and Technology on Global Freight Distribution.

FAO and IIR (2016). Developing the cold chain in the agrifood sector in sub-Saharan Africa. Yaoundé: Food and Agriculture Organization of the United Nations (FAO) and the International Institute of Refrigeration (IIR).

FlexSim 3D Simulation Software: User Manual, Version FlexSim 7.3.6. (2014, Octber 07).

George M (2000). Managing the Cold Chain for Quality and Safety: Flair-Flow Europe Technical Manual 378A/00. (R. Gormley, Ed.) Dublin: National Food Centre.

Hassan RR, Éva DS, Neam A, Hussein S, Miklós F (2015). Postharvest Management of Fruits and Vegetables Storage. Sustainable Agriculture Reviews, pp 65-152.

James S, James C, Evans J (2006). Modelling of food transportation systems - A review. International Journal of Refrigeration, 29(6): 947957.
Jobling $\mathrm{J}$ (n.d.). Correct cool chain management is essential for all fruit and vegetables. Retrieved March 1, 2017, from http://www.postharvest.com.au/Shelflife.PDF

$\mathrm{Ke} \mathrm{C} \mathrm{(2013).} \mathrm{Research} \mathrm{on} \mathrm{optimized} \mathrm{problem-solving} \mathrm{solutions:}$ Selection of the production process. Journal of Applied Research and Technology, 11(4): 523-532.

Kitinoja L, Kader AA (2003). Small-Scale Postharvest Handling Practices: A Manual for Horticultural Crops (4th Edition).

NCCD (2015). All India Cold-chain Infrastructure Capacity (Assessment of Status \& Gap). Delhi: (NCCD) National Centre for Cold-chain Development.

Paltrinieri G (n.d.). Handling of Fresh Fruits, Vegetables and Root Crops -A Training Manual- for Grenada. Grenada.

Pilgrim R (2010). A Manual for the Design, Establishment and Operation of Packing Houses and Processing Unit for Belize. Belize.

Reed C (2005). Mastering the Challenges of Temperature-Sensitive Distribution in Supply Chains. Cold Chains Are Hot!

Rodrigue JP, Notterboom T (2017). The Geography of Transport Systems (4th ed.). New york.

Sundarakani B, Tamimi M, Vel P (2010). Study of Cold Chain Logistics Implementation Strategies: Insights from UAE Industry. POMS 21st Annual Conference. Vancouver.

Wang S, Wang R (2005). Recent Developments of Refrigeration Technology in Fishing Vessels. Renewable Energy, 30(4): 589-600.

Yaptenco K, Esguerra E (2012). Good practice in the design, management and operation of a fresh produce packing-house. Bangkok: Rap Publication.

Zhu X, Zhang R, Chu F, He Z, Li J (2014). A Flexsim-based optimization for the operation process of cold-chain logistics distribution centre. Journal of Applied Research and Technology, 12(2): 270-278.
Citation: Asante AA, Yin M, Abbew CK, Nyumuteye D (2019). Optimizing the operational process of a cold chain fruit pack house. Afr J Eng Res, 7(3): 64-73. 